\title{
Facilitating knowledge transfer between researchers and wildfire practitioners about trust: An international case study
}

\author{
by Tara K. McGee ${ }^{1}$, Allan Curtis², Bonita L. McFarlane ${ }^{3}$, Bruce Shindler", \\ Amy Christianson ${ }^{3}$, Christine Olsen ${ }^{5}$ and Sarah McCaffrey ${ }^{6}$
}

\begin{abstract}
The importance of knowledge transfer between researchers, policy makers and practitioners is widely recognized. However, barriers to knowledge transfer can make it difficult for practitioners to apply the results of scientific research. This paper describes a project that addressed barriers to knowledge transfer by involving wildfire management practitioners from three countries in developing a trust planning guide. The guide provides information about trust, factors that influence trust and actions that can be taken to build trust in the context of wildfire management. The researchers synthesized academic research into a draft trust planning guide. Wildfire management practitioners and stakeholders provided feedback about the guide and discussed their own experiences in building trust in a workshop setting. The researchers incorporated valuable feedback from the workshops into the final trust planning guide. Benefits and challenges of this process are discussed, and the authors provide recommendations for researchers and funding agencies to facilitate the uptake of research by end-users.
\end{abstract}

Keywords: knowledge transfer, wildfire, trust, wildfire management

\section{RÉSUMÉ}

Personne ne met en doute l'importance du transfert de connaissances entre les chercheurs, les responsables des politiques et les spécialistes. Cependant, les obstacles au transfert de connaissances peuvent accentuer les difficultés quéprouvent les spécialistes à utiliser les résultats des recherches scientifiques. Cet article décrit un projet sur les obstacles au transfert des connaissances impliquant les spécialistes en gestion des feux de forêt de trois pays dans le développement d'un guide de planification pour bâtir un lien de confiance. Ce guide nous renseigne sur la confiance, sur les facteurs qui influencent la confiance et sur les démarches à faire pour établir un lien de confiance dans un contexte de gestion des feux de forêt. Les chercheurs ont résumé les travaux de recherche universitaire sous la forme d'un projet de guide de planification pour établir un lien de confiance. Les spécialistes et les intervenants en gestion des feux de forêt ont commenté le guide et ont discuté de leurs propres expériences en création de liens de confiance dans le cadre d'un atelier de travail. Les chercheurs ont intégré les commentaires constructifs issus de l'atelier dans la version définitive du guide de planification pour bâtir un lien de confiance. Les auteurs font ressortir les avantages et les défis liés à ce processus et soumettent des recommandations aux chercheurs et aux organismes subventionnaires afin de faciliter lutilisation des travaux de recherche par les utilisateurs finals.

Mots clés : transfert de connaissances, feu de forêt, confiance, gestion des feux de forêt

\footnotetext{
${ }^{1}$ Tara K. McGee, Department of Earth and Atmospheric Sciences, University of Alberta, Edmonton, Alberta.

Correspondence: tmcgee@ualberta.ca

${ }^{2}$ Allan Curtis, Institute for Land, Water and Society, Charles Sturt University, NSW, Australia.

${ }^{3}$ Bonita L. McFarlane, Natural Resources Canada, Canadian Forest Service, Alberta, Canada.

${ }^{4}$ Bruce Shindler, College of Forestry, Oregon State University, Oregon, USA.

${ }^{3}$ Amy Christianson, Natural Resources Canada, Canadian Forest Service, Alberta, Canada.

${ }^{5}$ Christine Olsen, College of Forestry, Oregon State University, Oregon, USA.

${ }^{6}$ Sarah McCaffrey, USDA Forest Service, Northern Research Station, USA.
} 


\section{Introduction}

\section{Knowledge transfer}

Ensuring that academic research informs policy and management is a perennial issue in many fields (e.g., Mitton et al. 2007, Wandersman et al. 2008), including wildfire management (Davis et al. 2013). Researchers have responded to the challenges of ensuring research informs practice, and identifying effective processes for knowledge transfer and exchange. For example, Wandersman et al. (2008) developed the Interactive Systems Framework for Dissemination and Implementation (ISF), which includes three systems or processes for knowledge transfer and exchange: synthesis and translation, support, and delivery. The synthesis and translation system distills information and innovations and translates it into user-friendly formats. The support system provides training, technical assistance or other support to users. The delivery system implements innovations in practice.

The literature also identifies barriers to knowledge transfer and exchange. For example, Fothergill (2000) identified four major groups of barriers to knowledge transfer: culture, institutions, links, and interaction. Fothergill's study established that researchers and practitioners had very different cultures or sub-cultures including beliefs, behaviours, goals, language, and priorities. In particular, technical jargon and academic writing style can pose challenges in distilling academic research into information useful to practitioners. Institutional barriers typically include time constraints and different reward systems for researchers and practitioners. For example, academic reward systems for researchers may focus on publishing in high quality journals with little rewards for publishing in venues more accessible to end-users (Cherney et al. 2012). Links refers to structures that facilitate interactions between academics and practitioners which can include knowledge translators and other intermediaries who can make research more accessible (Fothergill 2000, Davis et al. 2013). Insufficient interaction between researchers and practitioners has also been identified as a barrier to knowledge transfer (Landry et al. 2007, Cherney et al. 2012). Beyond Fothergill's four categories of barriers, a lack of resources to support knowledge transfer has also been recognized as a barrier (Cherney et al. 2012).

This paper describes a process to address the challenges of knowledge transfer from researchers to practitioners in a wildfire management context. We begin by reviewing the relationship between trust and natural resource management. Next, we describe the process used to develop a trust planning guide (Shindler et al. 2014) that would be useful for fire management practitioners in Australia, Canada and the United States. Finally, we explain how the cultural, institutional, links and interaction barriers were addressed in this project.

\section{Trust and wildfire management}

An extensive literature exists in psychology, political science and other fields about trust and factors that influence the development, maintenance and loss of trust (e.g., Warren 1999, Simpson 2007, Stern and Coleman 2015). Over the last decade a substantial body of research has been published focussed around trust building between natural resource managers, including wildfire practitioners, and local stakeholders (e.g., Olsen and Sharp 2013). Researchers have established that trust is an important influence on the outcomes of efforts to engage the public with wildfire management programs (e.g., Brunson and Evans 2005, Toman et al. 2011). As part of this body of work, social scientists have examined trust and factors that influence trust in the wildfire management context (e.g., Lachapelle and McCool 2012, Sharp et al. 2013).That research identifies trust as a critical element in establishing the positive stakeholder relationships fundamental to effective resource management. However, it is not clear if the results of existing research on trust are reaching practitioners.

\section{Synthesis and translation process}

In the first stage of the process, a team of researchers from three universities and two government agencies in Australia, Canada, and the United States worked together to identify and synthesize existing academic literature about trust, factors that influence trust, and actions that can be taken to build trust. This information was synthesized into a draft 14page guide with three sections. In the first section, we summarized the literature about the concept of trust including a definition of trust, different types of trust, trustworthy qualities, and the relevance of trust to management agencies. This section was intended to provide practitioners with a basic framework for ways to think about trust and the trust building process. The second section aimed to help the reader recognize current trust issues in their context by describing how trust is important for different types of fire management activities. In the third section, we identified actions that could be taken to establish and maintain trust in communities and lead to more effective fire management programs. Typically, this is where many researchers end the knowledge transfer process: a synthesis of academic literature which provides a state of the knowledge summary of the topic. The result may or may not be particularly relevant to the day-today realities of practitioners. Rather than following this oneway flow of information from researcher to practitioner, we also engaged practitioners in providing feedback about the guide and discussing their own trust experiences in a workshop setting. This stage was included to help ensure that the product of the research — a trust planning guide (see Shindler et al. 2014) - would best resonate and be useful for practitioners.

For the workshop stage of the process, we purposively identified regions in Australia, Canada and the United States where agency personnel had been interacting with stakeholders on fire management. The selected regions were Wangaratta, Victoria (Australia), Kananaskis, Alberta (Canada), and Bend, Oregon (United States). In Canada, the Kananaskis region was recommended by a government agency representative, and in the United States and Australia research team members were familiar with the fire management activities taking place in these regions. Agency personnel were contacted in each region to see if they were interested in working with us to organize a practitioner workshop to review the draft trust guide. Once they expressed interest in participating, they were asked to identify individuals from government agencies, non-government organizations and others who are involved in fire management in their region. Once these individuals were identified, a research team member invited each person to participate in a workshop held in September and October 2012. 
Each workshop included 12 to 15 participants (not including research team members) and lasted four to five hours. Prior to the workshops, participants were sent the draft trust planning guide to review and to stimulate their thinking about trust in their local context. Participants were encouraged to read and record their initial thoughts about trust and the draft planning guide directly on their copy. The workshops were conducted as facilitated focus groups and were led by the same research team member in all three countries. Workshop participants were asked to provide overall comments and specific input on each section of the guide. The facilitated discussion was free flowing as participants discussed their own experiences of trust and trust-building in their work. A field trip was also conducted in each region to provide the research team with the opportunity to learn about the local wildfire management context and trust building efforts of local agencies as well as an opportunity for informal interaction between the research team and practitioners.

During the workshops, research team members were observers and note takers. At the end of each workshop, time was spent with participants in reviewing "here's what we heard" to ensure that we had captured the main points raised by participants. Additionally, participants were asked to leave behind their draft trust guide that included their notes and personal comments. After each workshop the research team held a debriefing session to discuss points arising from the group discussions. After the final workshop we analyzed the workshop notes and comments written on the draft trust planning guide by participants. In this way we identified participants' perceptions of the strengths and weaknesses of the guide and suggestions for improving the document. Once the trust planning guide had been revised, two workshop participants from each country were asked to review the guide before it was finalized.

\section{Workshop outcomes \\ Relevance of a trust guide}

It was clear that both researchers and practitioners had shared interests in trust and trust building and the development of a trust planning guide. In the words of one workshop participant:

"I just loved that trust was coming in and being a priority put on the table. I think it goes from the very top to the person on the ground. It has to be there. It gives transparency. As a resident, I'm going to be dealing with the person on the ground... When I was reading this I was so excited to see it, because it was something I was fighting for..." (Canada)

The importance of trust and trust building was also apparent when participants shared their own stories about trust in their work environment. For example:

"After Black Saturday, I thought we wouldn't be welcomed back in those communities as an organization or as a person as a mouthpiece of the organization. But we had enough money in the bank, enough trust, that we were welcomed back immediately. And that allowed us to do all the great things we have done since." (Australia)
Workshop participants in all three countries said that the draft planning guide and workshop enabled them to think in a more structured way about trust building - something that they also want to achieve in their work but typically do not actively address. Participants also thought that the trust planning guide could be used to raise the importance of trust building within their workplace, organization, and beyond. A participant at the U.S. workshop said that senior staff in his organization would find it useful to go through the guide with fire practitioners. An Australian participant said that the trust guide would be useful at the regional level in her organization and would be particularly useful for new employees. Several participants also said that the trust guide would work well as a way of facilitating discussion in a workshop or discussion group.

Workshop participants identified aspects of the draft planning guide that they found particularly important and useful. The first section of the guide, which defined trust, explained how trust is built and the preconditions of trust (interdependence, uncertainty and risk) in a wildfire management context was identified as being very useful. In the words of one U.S. participant, "This section helped me frame what trust is and how it is built". However, participants also indicated that they would have liked to have seen the guide address key challenges they face in building trust. For example, loss of agency presence in communities was identified as a challenge in the Canadian and U.S workshops. In response, we added a new section about management challenges for trust building, drawing from examples discussed during the workshops. Participants unanimously appreciated suggestions in the guide about actions that they could take to build trust. However, they also thought this part of the guide could be expanded to include 'more concrete actions'. That feedback led to changes in the description of trust building actions in the guide. For example, graphics which showed actions that can be used to build trust were revised to clarify how actions relate back to the trustworthy qualities that many workshop participants found useful.

Each section of the draft planning guide included a list of key questions to encourage readers to consider how information provided might apply to their experiences and work context. This translation of research findings into a format (i.e., questions) that was directly relevant to practitioners' work context was identified as extremely useful by many workshop participants. In response we added a section in the final guide on "Assessment Tools" that provides additional information about how practitioners can monitor and evaluate progress and developed key questions to guide this process. In all three countries, participants called for training workshops to accompany the use of the guide and to facilitate uptake by practitioners. Although we agree that developing a workshop component is a logical next step in knowledge transfer, this was beyond the scope of the current project.

\section{Overcoming Cultural Barriers}

Differences in language and academic writing style have been identified as part of the cultural differences between researchers and practitioners (Littell et al. 2011). These differences became apparent during the workshops when differences amongst practitioners and between countries were 
identified. For example, workshop participants highlighted the different terms and different meanings of terms used to describe wildfire management professionals who work with communities in the three countries. In the U.S., the term 'manager' is used, and this term was subsequently included throughout the draft planning guide. However, in Australia and Canada a manager was perceived to be someone in a supervisory role, not the person working on the ground. Participants in Australia and Canada said that using 'manager' would suggest the guide was not relevant to locally-based practitioners. After much discussion we decided to use the term 'practitioners' on the basis that it is inclusive of both wildfire management personnel in management roles and those who work 'on the ground'.

Workshop participants in both Australia and Canada also felt that the draft planning guide was aimed at a higher organizational level than practitioners who do much of the dayto-day interacting with communities. In the words of one workshop participant in Canada:

"When I read the document, I found it too high up - $30000 \mathrm{ft}$. up level. I was looking for more meat. I'm a boots on the ground kind of guy. What would interest me would be some case studies as to how do you foster shared responsibility? What is the meat and potatoes of that? It's got some good information, but operationally to use, it might be quite difficult."

Participants in the three workshops also recommended that real examples of trust building should be added to make the information more accessible for practitioners. In response, the research team revised the guide to reduce the amount of theoretical material related to trust, and added case studies to provide examples of trust building at the local scale. As part of those revisions, the revised guide included a new section with examples from Australia, Canada, and the United States. Workshop participants also recommended that we add more graphics to the revised guide and reduce the amount of text. We took this advice and paid attention to the style of the guide, making it less like a research journal article and focused on producing a more appealing document by adding photographs and making format changes.

\section{Overcoming Institutional Barriers}

Differences in reward systems for researchers and practitioners have been identified as an institutional barrier to knowledge transfer. Our research team included both academic and government researchers. The academic team members are rewarded for publication in high-quality academic journals however they also place a high value on disseminating research to end-users. The main outcome of the effort was the trust planning guide and that document has been widely distributed and used by wildfire management practitioners in all three countries: the guide is being incorporated into a national fire leadership course in the U. S; in Canada, the guide has been distributed to wildfire management practitioners across the country; and, in Australia the guide was launched at a meeting of fire practitioners from the most fireprone states of New South Wales and Victoria. Recognition of the impact of research within the reward system of research team members also provided incentive to invest considerable effort in making the guide relevant to practitioners across the three countries.

\section{Role of Funding, Links, and Interactions}

Most funding agencies provide funds for knowledge transfer via final project reports, journal articles, and conference presentations but seldom fund larger scale knowledge transfer initiatives. Importantly, we were able to secure funding specifically for a knowledge transfer project from the Joint Fire Science Program -the research cooperative of the five federal agencies that manage lands affected by wildfire in the U.S. The Joint Fire Science Program supports research tailored to the needs of fire and fuel managers and delivers research findings to ensure that managers are aware of, understand, and can use the information to make sound decisions and implement projects (http://www.firescience.gov/JFSP_program_ info.cfm). The Joint Fire Science Program also played a key role in disseminating the trust planning guide to management agencies throughout the U.S. and featuring this project at several conferences with large numbers of participants.

Research team members have extensive personal and institutional networks with wildfire management practitioners, including through their employment in lead agencies responsible for fire management in the U.S.; ongoing wildfire research projects in Australia, Canada and the U. S; and their commitment to supporting local practitioners in regions where they work and live. These linkages were integral in providing team members in each of the countries with a strong practitioner network from which to recruit workshop participants. In the words of one research team member:

"A large part of the success of our engagement with practitioners in Australia, in terms of our ability to gain their participation in the workshop and to critically review the draft guide, was that we drew upon established relationships where we had demonstrated our ability to undertake high quality applied research, a willingness to act in the best interests of our partners (e.g., by providing in-service training; assisting them to be informed purchasers of social research; investigating research topics they thought were important) and were respected for our independence and integrity in terms of our interactions with practitioners and their stakeholders."

\section{Conclusions}

The trust planning guide (Shindler et al. 2014) was prepared by a team of researchers from three universities and two government agencies with input from wildfire management practitioners in Australia, Canada and the US. We used a three-stage synthesis and translation process to develop the guide. First, existing academic literature was synthesized and a draft trust planning guide prepared. Second, workshops were organized with fire agency personnel and stakeholders involved in fire management to obtain feedback about the draft guide and discuss trust in the wildfire management context. Third, the research team revised the trust planning guide to respond to suggestions and comments raised during the workshops.

Through this process, the research team was able to address some of the barriers that have been found to limit knowledge transfer, thus providing benefits to both researchers and practitioners. Despite institutional fire management differences across the countries, it was clear that trust was a vital component in fire management at the com- 
munity level in the three countries. However, if we had not held the workshops and field trips, we would have missed more subtle cultural and terminology differences between countries. For example, the guide might have been overlooked by locally-based practitioners in Australia and Canada if they perceived the document as being only relevant to high level managers in their organizations. This feedback process also helped make the revised guide more accessible by including examples of how trust has been built on the ground and what happens when trust building does not occur. Other suggestions that were adopted related to increasing the use of graphics and reducing the amount of text. This process enabled the research team to better meet the needs of fire practitioners by expanding the sections on actions that build trust and management challenges to trust building; and expanding the section on assessment tools to monitor and evaluate progress. Learning about and incorporating practitioners' own experiences and knowledge of trust building led to significant changes in the material covered in the guide and its format. This highlights the importance of knowledge transfer as a partnership that facilitates shared meanings of research findings within different contexts. Based on feedback to the final guide we are confident that these changes have resulted in a guide to trust building that will effectively transfer relevant research findings to wildfire management practitioners.

The priority given to peer-reviewed academic publications by universities may be a key institutional barrier for many academic researchers committed to knowledge transfer to practitioners. In this project, the research team sought funding from the Joint Fire Science Program to develop a practitioner guide to trust building. That is, the researchers deliberately set out to meet this challenge and were supported by the funding body. That is not always the case. As explained above, the research team's networks and regular interactions with practitioners also meant that we were well-placed to effectively engage practitioners in the process of developing the guide.

Despite the achievement of creating a guide that practitioners find useful, developing a knowledge transfer tool across three countries required a significant investment of time and financial resources. However we believe that an approach similar to the one we used will improve the transfer of knowledge from researchers to practitioners in many contexts. The outcome of this process, the trust guide (Shindler et al. 2014), provides information about trust and trust building in an accessible format, which practitioners will be able to use in their work. In particular, the guide includes actions that practitioners can take to build trust, and a list of key questions that practitioners can use to generate discussion in their workplace about trust building.

\section{Acknowledgements}

The authors would like to thank the workshop participants for providing us with extremely valuable feedback on the draft planning guide and insights into how they build trust on the ground. Special thanks to the agency representatives in each country that helped to recruit workshop participants and organized the field visits for the research team. Thank you to the Joint Fire Science Program for funding this project (ID\# 10-3-01-25) and helping to disseminate the trust guide to fire practitioners.

\section{References}

Brunson, M.W. and J. Evans. 2005. Badly burned? Effects of an escaped prescribed burn on the social acceptability of wildland fuels treatments. J. Forest. 103:134-138.

Cherney, A., B. Head, P. Boreham, J. Povey and M. Ferguson. 2012. Perspectives of academic social scientists on knowledge transfer and research collaborations: A cross-sectional survey of Australian academics. Evidence \& Policy 8(4): 433-453. Doi:10.1332/ 174426412 X660098

Davis, E.J., C. Moseley, C. Olsen, J. Abrams and J. Creighton. 2013. Diversity and dynamism of fire science user needs. J. Forest. 111(2): 101-107. Doi:10.5849/jof.12-037

Fothergill, A. 2000. Knowledge transfer between researchers and practitioners. Nat. Hazards Rev. 1(2): 91-98. Doi:10.1061/(ASCE) 1527-6988(2000)1:2(91)

Lachapelle, P.R. and S.F. McCool. 2012. The role of trust in community wildland fire protection planning. Soc. Natur. Resour. 25: 321-335. Doi: 10.1080/08941920.2011.569855

Landry, R., N. Amara and M. Ouimet. 2007. Determinants of knowledge transfer: evidence from Canadian university researchers in natural sciences and engineering. J. Technol. Transfer 32(6): 561-592. Doi: 10.1007/s10961-006-0017-5

Littell, J., D. Peterson, C. Millar and K. O’Halloran. 2011. U.S. National Forests adapt to climate change through science-management partnerships. Climate Change. Doi:10.1007/s10584-011-0066-0. Mitton, C., C.E. Adair, E. McKenzie, S.B. Patten and B.W. Perry. 2007. Knowledge transfer and exchange: Review and synthesis of the literature. Milbank Q. 85(4): 729-768. Doi: 10.1111/j.14680009.2007.00506.x

Olsen, C.S. and E. Sharp. 2013. Building community-agency trust in fire-affected communities in Australia and the United States. Int. J. Wildland Fire 22(6): 822-831. Doi: http://dx.doi.org/10.1071/WF12086 Sharp, E.A., R. Thwaites, A. Curtis and J. Millar. 2013. Trust and trustworthiness: Conceptual distinctions and their implications for natural resource management. J. Environ. Plann. Man. 56: 1246-1265. Doi: 10.1080/09640568.2012.717052

Shindler, B., C. Olsen, S. McCaffrey, B. McFarlane, A. Christianson, T. McGee, A. Curtis and E. Sharp. 2014. Trust: A Planning Guide for Wildfire Agencies and Practitioners - An International Collaboration Drawing on Research and Management Experience in Australia, Canada, and the United States. A Joint Fire Science Program Research Publication, Oregon State University, Corvallis, OR. Available at: https://www.firescience.gov/projects/10-3-01-25/project/10-3-01-25_Trust_Planning_Guide.pdf.

Simpson, J.A. 2007. Psychological Foundations of Trust. Curr. Dir. Psychol. Sci. 16(5): 264-268. Doi: 10.1111/j.1467-8721.2007.00517.x Stern, M.J. and K.J. Coleman. 2015. The Multidimensionality of Trust: Applications in Collaborative Natural Resource Management. Soc. Natur. Resour. 28(2): 117-132. Doi: 10.1080/08941920.2014.945062 Toman, E., M. Stidham, B. Shindler and S. McCaffrey. 2011. Reducing fuels in the wildland-urban interface: community perceptions of agency fuels treatments. Int. J. Wildland Fire 20: 340-349. Doi: 10.1071/WF10042

Wandersman, A., Duffy, J., Flaspohler, P., Noonan, R., Lubell, K., Stillman, L., Blachman, M., Dunville, R. Saul and J. Saul. 2008. Bridging the gap between prevention research and practice: The interactive systems framework for dissemination and implementation. Am. J. Commun. Psychol. 41(3-4): 171-181. Doi: 10.1007/ s10464-008-9174-Z

Warren, M.E. 1999. Democracy and Trust. Cambridge University Press, Cambridge, UK. 